\title{
Sirt3 attenuates hydrogen peroxide-induced oxidative stress through the preservation of mitochondrial function in HT22 cells
}

\author{
SHU-HUI DAI ${ }^{*}$, TAO CHEN $^{1,2^{*}}$, YU-HAI WANG ${ }^{3 *}$, JIE ZHU $^{3}$, PENG LUO $^{1}$, \\ WEI RAO ${ }^{1}$, YUE-FAN YANG ${ }^{1}$, ZHOU FEI $^{1}$ and XIAO-FAN JIANG ${ }^{1}$ \\ ${ }^{1}$ Department of Neurosurgery, Xijing Institute of Clinical Neuroscience, \\ Xijing Hospital, Fourth Military Medical University, Xi'an, Shaanxi 710032; ${ }^{2}$ Department of Surgery, \\ The 123th Hospital of PLA, Bengbu, Anhui 233000; ${ }^{3}$ Department of Neurosurgery, The 101th Hospital of PLA, \\ Rescue Center of Craniocerebral Injuries of PLA, Wuxi, Jiangsu 214044, P.R. China
}

Received May 24, 2014; Accepted July 14, 2014

DOI: $10.3892 /$ ijmm.2014.1876

\begin{abstract}
Sirtuins (Sirt) are a family of phylogenetically conserved nicotinamide adenine nucleotide $\left(\mathrm{NAD}^{+}\right)$-dependent protein deacetylases, among which Sirt3 resides primarily in the mitochondria and serves as a stress responsive deacetylase, playing a role in protecting cells from damage under stress conditions. The present study aimed to investigate the role of Sirt3 in hydrogen peroxide $\left(\mathrm{H}_{2} \mathrm{O}_{2}\right)$-induced oxidative neuronal injury in HT22 mouse hippocampal cells. Treatment with $\mathrm{H}_{2} \mathrm{O}_{2}$ increased the expression of Sirt 3 in a dose- and time-dependent manner, and the knockdown of Sirt3 using specific small interfering RNA (siRNA) exacerbated the $\mathrm{H}_{2} \mathrm{O}_{2}$-induced neuronal injury. The overexpression of Sirt3 induced by lentiviral transfection significantly reduced the generation of reactive oxygen species (ROS) and lipid peroxidation following injury, whereas the activities of endogenous antioxidant enzymes were not affected. Further experiments revealed that the $\mathrm{H}_{2} \mathrm{O}_{2}$-induced inhibition of mitochondrial complex activity and adenosine triphosphate (ATP) synthesis, the decrease in mitochondrial $\mathrm{Ca}^{2+}$ buffering capacity and mitochondrial swelling were all partly reversed by Sirt3. Furthermore, the overexpression of Sirt3 attenuated the release of cytochrome $c$, the increase in the $\mathrm{Bax} / \mathrm{Bcl}-2$ ratio, as well as caspase-9/caspase-3 activity induced by $\mathrm{H}_{2} \mathrm{O}_{2}$, and eventually inhibited apoptotic neuronal cell death. These results suggest that Sirt3 acts as a prosurvival factor, playing an essential role in protecting $\mathrm{HT} 22$ cells under $\mathrm{H}_{2} \mathrm{O}_{2}$-induced
\end{abstract}

Correspondence to: Professor Xiao-Fan Jiang or Professor Zhou Fei, Department of Neurosurgery, Xijing Institute of Clinical Neuroscience, Xijing Hospital, Fourth Military Medical University, 169 Changle West Road, Xi'an, Shaanxi 710032, P.R. China

E-mail: fmmujiangxiaofan@163.com

E-mail: fmmuzhoufei@163.com

*Contributed equally

Key words: Sirt3, reactive oxygen species, oxidative stress, mitochondria oxidative stress, possibly by inhibiting ROS accumulation and the activation of the mitochondrial apoptotic pathway.

\section{Introduction}

Reactive oxygen species (ROS) are a group of molecules generated in the process of oxygen metabolism, among which the endogenous stable oxidant, hydrogen peroxide $\left(\mathrm{H}_{2} \mathrm{O}_{2}\right)$, is considered as the principal ROS member and has been the main focus of studies on ROS biology in recent years (1). For many years after its discovery, $\mathrm{H}_{2} \mathrm{O}_{2}$ was viewed as a non-specific agent of destruction to human tissues (2); however, growing evidence over the past few years suggests that $\mathrm{H}_{2} \mathrm{O}_{2}$ may act as a 'Jekyll and Hyde' signaling molecule in cell proliferation, migration, survival and death (1). At low concentrations, $\mathrm{H}_{2} \mathrm{O}_{2}$ can act as a classical second messenger with a pro-survival role by regulating kinase-driven pathways in several physiological processes. At high concentrations, $\mathrm{H}_{2} \mathrm{O}_{2}$ induces cellular injury by damaging key cellular molecules, such as DNA and lipids, and by inducing apoptosis, necrosis or autophagy. Several pharmacological agents targeting $\mathrm{H}_{2} \mathrm{O}_{2}$ metabolism have been demonstrated to have therapeutic potential in the treatment of neurological disorders, ranging from acute insults, such as ischemic and traumatic brain injury to chronic neurodegenerative disorders, such as Alzheimer's disease and Parkinson's disease $(3,4)$.

Mitochondria are usually described as 'cellular power plants' due to their ability to generate most of the chemical energy of cells, namely adenosine triphosphate (ATP), and they can also receive cellular signals and propagate a targeted response to mediate several basic cellular functions (5). Due to their important role in regulating cell metabolism and ROS generation, the damage and ensuing dysfunction of the mitochondria in neurons has been demonstrated to be a key factor in various types of oxidative stress related to neurological diseases (6). Following oxidative stress, the majority of the mitochondria develop varying degrees of swelling, and several pro-apoptotic molecules are released or activated, such as cytochrome $c$, caspase-9 and the pro-apoptotic Bcl-2 family of proteins (which includes Bax). A number of studies have demonstrated that many pharmacological agents and mitochondria-associated 
molecules exert protective effects against neuronal injury through the preservation of mitochondrial function, and this may be an ideal neuroprotective strategy (6,7).

The sirtuins (or Sir2-like proteins) are a conserved family of nicotinamide adenine nucleotide $\left(\mathrm{NAD}^{+}\right)$-dependent protein deacetylases, and have been reported to be involved in transcriptional silencing, the genetic control of aging and the longevity of organisms ranging from yeast to humans (8). Among these sirtuins, Sirt3 resides primarily in the mitochondria and serves as a primary regulator of mitochondrial function and metabolism by binding and deacetylating several metabolic and respiratory enzymes (9). The increased expression of Sirt3 protects cardiomyocytes against genotoxic and oxidative stressmediated cell death by hindering the translocation of Bax to the mitochondria (10). A recent study demonstrated that the Sirt3-mediated deacetylation of forkhead box O3 (FOXO3) attenuates oxidative stress-induced mitochondrial dysfunction through the coordination of mitochondrial biogenesis, fission/ fusion and mitophagy (11). However, the exact role of Sirt3 in oxidative stress-induced neuronal cell injury has not yet been fully elucidated. Therefore, the aim of the present study was to investigate the effects of Sirt3 knockdown and its overexpression in $\mathrm{H}_{2} \mathrm{O}_{2}$-induced neuronal injury in HT22 cells, as well as the potential mechanisms involved with focus on mitochondrial oxidative phosphorylation, calcium metabolism and the intrinsic apoptotic pathway.

\section{Materials and methods}

Cell culture. HT22 mouse hippocampal cells were obtained from the Institute of Biochemistry and Cell Biology (IBCB), Shanghai Institutes for Biological Sciences, Chinese Academy of Sciences (CAS), Shanghai, China. The cells were grown in Dulbecco's modified Eagle's medium (DMEM) plus 10\% fetal bovine serum and $1 \%$ antibiotics (penicillin/streptomycin) in a humidified incubator with $5 \% \mathrm{CO}_{2}$ and $95 \%$ air. The growth medium was removed and replaced by medium containing $\mathrm{H}_{2} \mathrm{O}_{2}$ for the induction of apoptosis.

Cell viability assay. Cell viability assay was performed using the Cell Proliferation Reagent WST-1 following the manufacture's instructions (Roche, Basel, Switzerland). Briefly, the HT22 cells were cultured at a concentration of $0.5-5 \times 10^{4}$ in microplates in a final volume of $100 \mu \mathrm{l} /$ well culture medium. Following the various treatments, $10 \mu \mathrm{l}$ of the cell proliferation reagent, WST-1, were added to each well followed by incubation for $4 \mathrm{~h}$ at $37^{\circ} \mathrm{C}$. Subsequently, $100 \mu \mathrm{l} /$ well culture medium and $10 \mu \mathrm{l}$ WST-1 were added to one well in the absence of HT22 cells, and its absorbance was used as a blank position for the ELISA reader. The cells were shaken thoroughly for $1 \mathrm{~min}$ on a shaker and the absorbance of the samples was measured using a microplate (ELISA) reader (Bio-Rad Laboratories, Cambridge, MA, USA).

Lactate dehydrogenase $(L D H)$ release assay. Cytotoxicity was determined by the release of $\mathrm{LDH}$, a cytoplasmic enzyme released from cells, and a marker of membrane integrity. The LDH release into the culture medium was detected using a diagnostic kit according to the manufacturer's instructions (Nanjing Jiancheng Bioengineering Institute, Nanjing, China). Briefly, $50 \mu \mathrm{l}$ of supernatant from each well were collected to measure the release of LDH. The samples were incubated with a reduced form of nicotinamide adenine dinucleotide (NADH) and pyruvate for $15 \mathrm{~min}$ at $37^{\circ} \mathrm{C}$ and the reaction was terminated by the addition of $0.4 \mathrm{~mol} / 1 \mathrm{NaOH}$. The activity of LDH was calculated from the absorbance at $440 \mathrm{~nm}$ and the background absorbance from the culture medium that was not used for any cell cultures was subtracted from all the absorbance measurements. The results were normalized to the maximal LDH release, which was determined by treating the control wells for 60 min with $1 \%$ Triton X-100 to lyse all cells.

Small interfering RNA (siRNA) and transfection. Specific siRNA targeting Sirt3 (Si-Sirt3, sc-61556) and control siRNA (Si-Control, sc-37007), which should not knock down any known proteins, were purchased from Santa Cruz Biotechnology, Inc. (Santa Cruz, CA, USA). The above-mentioned siRNA molecules were transfected into the cells using Lipofectamine 2000 (Invitrogen, Carlsbad, CA, USA) in 6-well plates for $48 \mathrm{~h}$. Following transfection, the HT22 cells were treated with $\mathrm{H}_{2} \mathrm{O}_{2}$ $(500 \mu \mathrm{M})$ for $24 \mathrm{~h}$ and subjected to various measurements.

Lentivirus construction and transfection. The coding sequence of Sirt3 was amplified by RT-PCR. The primer sequences were as follows: forward, 5'-TACTTCCTTCGGCTGCTTCA-3' and reverse, 5'-AAGGCGAAATCAGCCACA-3'. The PCR fragments and the pGC-FU plasmid (Shanghai Genechem Co.,Ltd., Shanghai, China) were digested with AgeI and then ligated with T4 DNA ligase to produce pGC-FU-Sirt3. To generate the recombinant lentivirus, LV-Sirt3, 293T cells were cotransfected with the pGC-FU plasmid $(20 \mu \mathrm{g})$ with a cDNA encoding Sirt3, pHelper1.0 plasmid $(15 \mu \mathrm{g})$ and pHelper 2.0 plasmid $(10 \mu \mathrm{g})$ using Lipofectamine $2000(100 \mu \mathrm{l})$. The supernatant was harvested and the viral titer was calculated by transducing 293T cells. As a control, we also generated a control lentiviral vector that expresses GFP alone (LV-Control). The HT22 cells were transfected with the lentiviral vectors for $72 \mathrm{~h}$ and subjected to various treatments.

Measurement of the $N A D^{+} / N A D H$ ratio. To investigate whether Sirt3 is enzymatically active under our experimental conditions, measurement of the $\mathrm{NAD}^{+} / \mathrm{NADH}$ ratio was performed using the $\mathrm{NAD}^{+} / \mathrm{NADH}$ Quantification kit (BioVision, Milpitas, CA, USA) according to the manufacturer's instructions. Briefly, $5 \times 10^{5}$ HT22 cells seeded in 6-well plates were washed with cold PBS, collected and centrifuged at 1,500 rpm for $5 \mathrm{~min}$. The cells were then lysed by 2 freeze/thaw cycles in $\mathrm{NADH} / \mathrm{NAD}$ extraction buffer and subsequently vortexed for $10 \mathrm{sec}$. The cellular extracts were transferred into a 96-well plate in duplicate, and incubated with NAD Cycling Mix for 5 min. $\mathrm{NAD}^{+}{ }_{\text {total }}$ was quantified by the addition of NADH developer to each sample and by reading the plate at OD450 $\mathrm{nm}$ for $30 \mathrm{~min}$. To detect $\mathrm{NADH}$, the extracted samples were incubated at $60^{\circ} \mathrm{C}$ for $30 \mathrm{~min}$ in order to decompose NAD . Subsequently, the samples were incubated with NAD Cycling Mix for $5 \mathrm{~min}$ and, after the addition of NADH developer, were read as previously described (12). The $\mathrm{NAD}^{+} / \mathrm{NADH}$ ratio was calculated as follows: $\left(\mathrm{NAD}^{+}{ }_{\text {total }}-\mathrm{NADH}\right) / \mathrm{NADH}$.

Measurement of ROS generation. Briefly, the HT22 cells were incubated with 2,7-dichlorodihydrofluorescein diace- 
tate (DCF-DA) (Sigma, St. Louis, MO, USA) $(10 \mu \mathrm{M})$ for $1 \mathrm{~h}$ at $37^{\circ} \mathrm{C}$ in the dark and then resuspended in phosphate-buffered saline (PBS). Intracellular ROS production was detected using the fluorescence intensity of the oxidant-sensitive probe, $\mathrm{H}_{2}$ DCF-DA, in a microscope and fluorescence was read using an excitation wavelength of $480 \mathrm{~nm}$ and an emission wavelength of $530 \mathrm{~nm}$.

Measurement of lipid peroxidation. Malonyldialdehyde (MDA) and 4-hydroxynonenal (4-HNE), 2 indexes of lipid peroxidation, were determined using assay kits from Cell Biolabs (San Diego, CA, USA) strictly following the manufacturer's instructions. The absorbance of the samples was measured using a microplate (ELISA) reader.

Detection of antioxidant enzyme activity. The enzyme activity of superoxide dismutase (SOD), catalase (CAT), glutathione peroxidase (GPx) and glutathione S-transferase (GST) was determined using commercially available assay kits following the manufacturer's instructions (Cayman Chemical Co., Mountain View, CA, USA). The protein concentration was determined using the BCA protein kit (Nanjing Jiancheng Bioengineering Institute). The enzyme activities were then normalized to the corresponding protein concentration for each sample.

Determination of mitochondrial respiratory chain complex activity. The mitochondria were purified by Percoll density gradient centrifugation in extraction buffer $(50 \mathrm{mM}$ Tris $\mathrm{HCl}$, pH 7.5, $500 \mathrm{mM} \mathrm{NaCl}, 0.03 \%$ reduced Triton $\mathrm{X}-100,1 \mathrm{mM}$ EDTA, $1 \mathrm{mM}$ PMSF, $0.5 \mathrm{mM}$ benzamidine, and $1 \mathrm{mg} / \mathrm{ml}$ each of pepstatin-A, leupeptin and aprotinin). All the samples were subjected to 3 freeze-thaw cycles to disrupt the membranes and expose the enzymes before analysis. The enzymatic activity was measured at $37^{\circ} \mathrm{C}$ spectrophotometrically using the following methods: complex I (NADH dehydrogenase), complex II (succinate dehydrogenase), complex III (ubiquinol cytochrome $c$ reductase) and complex IV (cytochrome $c$ oxidase), as previously described (13-15). The data were expressed as a percentage of the control.

Measurement of ATP synthesis. Isolated mitochondria were utilized to measure ATP synthesis with a luciferase/luciferinbased system as previously described (16). Mitochondriaenriched pellets $(30 \mu \mathrm{g})$ were resuspended in $100 \mu \mathrm{l}$ of buffer $\mathrm{A}$ (150 mM KCl, $25 \mathrm{mM}$ Tris- $\mathrm{HCl}, 2 \mathrm{mM}$ potassium phosphate, $0.1 \mathrm{mM} \mathrm{MgCl}_{2}, \mathrm{pH} 7.4$ ) with $0.1 \% \mathrm{BSA}, 1 \mathrm{mM}$ malate, $1 \mathrm{mM}$ glutamate and buffer B (containing $0.8 \mathrm{mM}$ luciferin and $20 \mathrm{mg}$ / $\mathrm{ml}$ luciferase in $0.5 \mathrm{M}$ Tris-acetate $\mathrm{pH} 7.75$ ). The reaction was initiated by the addition of $0.1 \mathrm{mM}$ adenosine diphosphate (ADP) and monitored for $5 \mathrm{~min}$ using a microplate reader (Bio-Rad Laboratories).

Measurement of mitochondrial swelling. Mitochondrial swelling was measured following a previously published protocol (17). Briefly, the isolated mitochondria were suspended in fresh swelling buffer (0.2 $\mathrm{M}$ sucrose, $10 \mathrm{mM}$ Tris-MOPS, $\mathrm{pH} 7.4,5 \mathrm{mM}$ succinate, $1 \mathrm{mM}$ phosphate, $2 \mu \mathrm{M}$ rotenone and $1 \mu \mathrm{M}$ EGTA-Tris, $\mathrm{pH} 7.4$ ) at $0.5 \mathrm{mg} / \mathrm{ml}$, and the swelling of the mitochondria was monitored by a decrease in absorbance at $540 \mathrm{~nm}$ in the presence of calcium chloride $\left(\mathrm{CaCl}_{2} ; 200 \mu \mathrm{M}\right)$.
Measurement of mitochondrial calcium buffering capacity. Mitochondrial calcium buffering capacity was estimated using the $\mathrm{Ca}^{2+}$ sensitive Calcium Green $5 \mathrm{~N}$ fluorescent dye. The incubation medium was composed of $125 \mathrm{mM} \mathrm{KCl,} 20 \mathrm{mM}$ HEPES (pH 7.2), $2 \mathrm{mM} \mathrm{KH}_{2} \mathrm{PO}_{4}, 2 \mathrm{mM} \mathrm{MgCl} 2,5 \mathrm{mM}$ succinate, $1 \mu \mathrm{M}$ rotenone and $0.2 \mathrm{mM}$ ADP, with $1 \mu \mathrm{g} / \mathrm{ml}$ oligomycin and $1 \mu \mathrm{M}$ Calcium Green 5N. Bolus additions of $\mathrm{CaCl}_{2}$ were made to the $60 \mu \mathrm{g}$ of mitochondria in suspension in $30 \mathrm{nM}$ increments and changes in Calcium Green $5 \mathrm{~N}$ fluorescence were recorded at an emission of $532 \mathrm{~nm}$.

Flow cytometry. The HT22 cells were harvested $24 \mathrm{~h}$ following exposure to $\mathrm{H}_{2} \mathrm{O}_{2}$, washed with ice-cold $\mathrm{Ca}^{2+}$ free $\mathrm{PBS}$, and re-suspended in binding buffer. Cell suspension was transferred into a tube and double-stained for $15 \mathrm{~min}$ with Alexa Fluor 488-conjugated Annexin V (AV) and propidium iodide (PI) at room temperature in the dark. After the addition of $400 \mu \mathrm{l}$ binding buffer, the stained cells were analyzed using an FC500 flow cytometer (Beckman-Coulter, Brea, CA USA) with the fluorescence emission at $530 \mathrm{~nm}$ and $>575 \mathrm{~nm}$. CXP cell quest software (Beckman-Coulter) was used to count the number of apoptotic cells $\left(\mathrm{AV}^{+} / \mathrm{PI}^{+}\right.$, late phase apoptotic cells and $\mathrm{AV}^{+} / \mathrm{PI}^{-}$, early phase apoptotic cells) and analyzed the results.

Quantification of cytochrome c release. Cytochrome $c$ release into the cytoplasm was assessed following subcellular fraction preparation. The HT22 cells were washed with ice-cold PBS 3 times and lysed with lysis buffer containing protease inhibitors. The cell lysate was centrifuged for $10 \mathrm{~min}$ at $750 \mathrm{x}$ g at $4^{\circ} \mathrm{C}$, and the pellets containing the nuclei and unbroken cells were discarded. The supernatant was then centrifuged at $15,000 \mathrm{x} \mathrm{g}$ for $15 \mathrm{~min}$. The resulting supernatant was removed and used as the cytosolic fraction. The pellet fraction containing the mitochondria was further incubated with PBS containing $0.5 \%$ Trition $\mathrm{X}-100$ for $10 \mathrm{~min}$ at $4^{\circ} \mathrm{C}$. Following centrifugation at $16,000 \mathrm{x}$ g for $10 \mathrm{~min}$, the supernatant was collected as the mitochondrial fraction. The levels of cytochrome $c$ in the cytosolic and mitochondrial fractions were measured using the Quantikine M Cytochrome C Immunoassay kit obtained from R\&D Systems (Minneapolis, MN, USA). Data were expressed as $\mathrm{ng} / \mathrm{mg}$ protein.

Measurement of caspase-3 activity. The activity of caspase-3 was measured using the colorimetric assay kit according to the manufacturer's instructions (Cell Signaling Technology, Danvers, MA, USA). Briefly, after being harvested and lysed $10^{6}$ cells were mixed with $32 \mu \mathrm{l}$ of assay buffer and $2 \mu \mathrm{l}$ of $10 \mathrm{mM}$ Ac-DEVD-pNA substrate. Absorbance at $405 \mathrm{~nm}$ was measured following incubation at $37^{\circ} \mathrm{C}$ for $4 \mathrm{~h}$. The absorbance of each sample was determined by subtraction of the mean absorbance of the blank and corrected by the protein concentration of the cell lysate. The results were described as the relative activity to that of the control group.

Western blot analysis. Equivalent amounts of protein (40 $\mu \mathrm{g}$ per lane) were loaded and separated by $10 \%$ SDS-PAGE gels, and transferred onto polyvinylidene difluoride (PVDF) membranes. The membranes were blocked with $5 \%$ non-fat milk solution in Tris-buffered saline with $0.1 \%$ Triton X-100 (TBST) for $1 \mathrm{~h}$, 

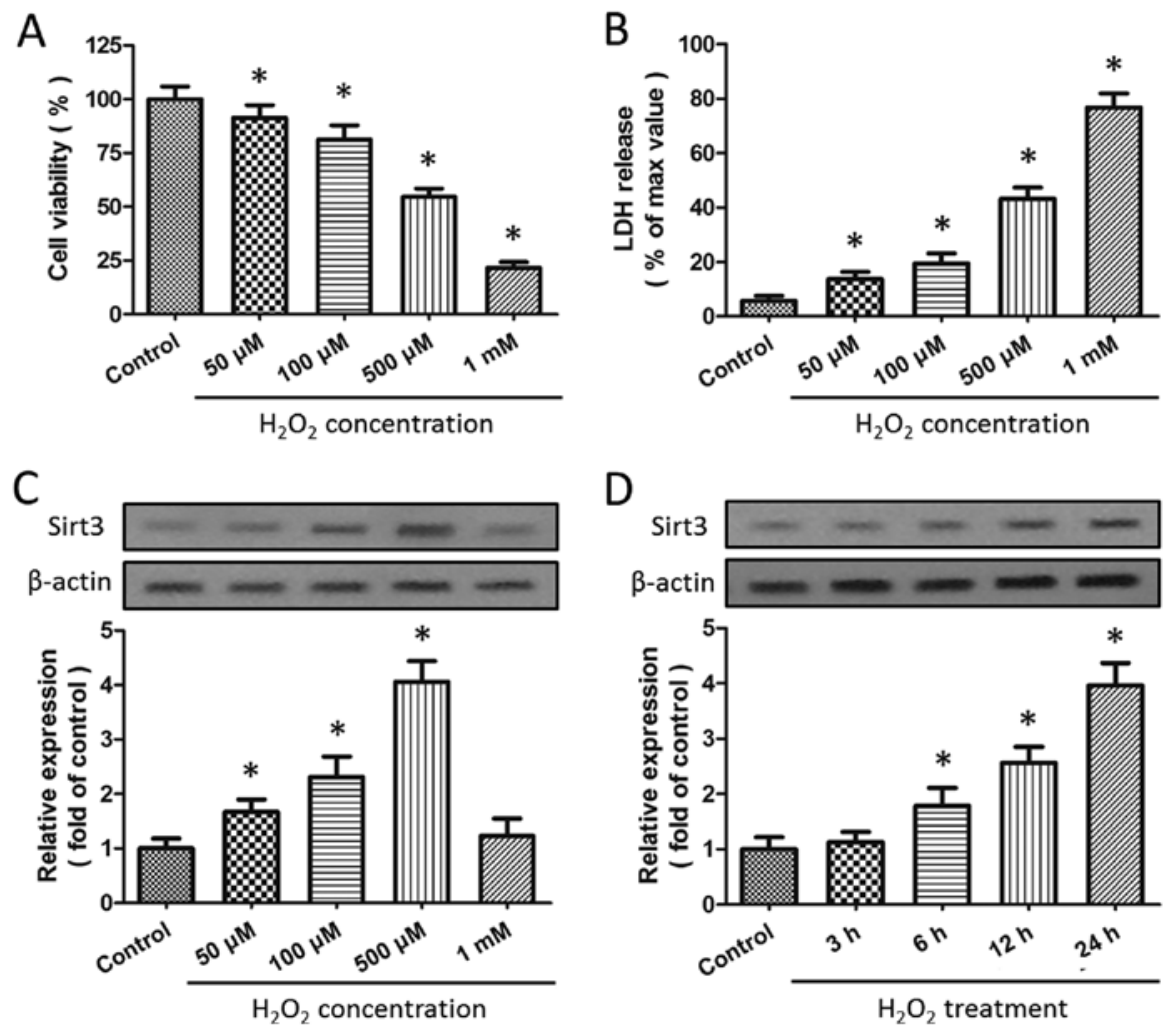

Figure 1. Expression of Sirt3 following $\mathrm{H}_{2} \mathrm{O}_{2}$-induced injury in $\mathrm{HT} 22$ cells. $\mathrm{HT} 22$ cells were treated with $\mathrm{H}_{2} \mathrm{O}_{2}$ at various concentrations for 24 h. Cell viability was measured by (A) WST-1 assay and (B) cytotoxicity was measured by lactate dehydrogenase (LDH) assay. (C) The expression of Sirt3 was measured by western blot analysis. (D) HT22 cells were treated with $500 \mu \mathrm{M} \mathrm{H}_{2} \mathrm{O}_{2}$, and the expression of Sirt3 was measured by western blot analysis. Data are shown as the means \pm SD of 5 experiments. ${ }^{*} \mathrm{P}<0.05$ vs. control.

and then incubated overnight at $4^{\circ} \mathrm{C}$ with primary Sirt3 antibody (1:1,000), Bax (1:800), Bcl-2 (1:800), cleaved caspase-9 (1:500) or caspase-9 (1:600) antibody dilutions in TBST. Subsequently, the membranes were washed and incubated with secondary antibody (anti-rabbit and anti-goat IgG; Santa Cruz Biotechnology) for $1 \mathrm{~h}$ at room temperature. Immunoreactivity was detected with Super Signal West Pico chemiluminescent substrate (Thermo Fisher Scientific, Rockford, IL, USA). The band densities were corrected for the $\beta$-actin signals. ImageJ analysis software (Scion Corp.) was used to quantify the optical density of each band.

Statistical analysis. Statistical analysis was performed using the SPSS 16.0, a statistical software package. Statistical evaluation of the data was performed by one-way analysis of variance (ANOVA) followed by Bonferroni's multiple comparisons. A value of $\mathrm{P}<0.05$ was considered to indicate a statistically significant difference.

\section{Results}

Expression of Sirt3 following $\mathrm{H}_{2} \mathrm{O}_{2}$-induced injury in HT22 cells. The HT22 cells were incubated in the presence of $\mathrm{H}_{2} \mathrm{O}_{2}$ at various concentrations $(50,100,500 \mu \mathrm{M}$ or $1 \mathrm{mM})$ for $24 \mathrm{~h}$, and the cytotoxicity was determined by WST-1 assay and LDH release assay. The results revealed that incubation with $\mathrm{H}_{2} \mathrm{O}_{2}$ significantly decreased cell viability (Fig. 1A) and increased LDH release (Fig. 1B) (both $\mathrm{P}<0.05)$ in a dose-dependent manner. As the exposure of the cells to $500 \mu \mathrm{M} \mathrm{H}_{2} \mathrm{O}_{2}$ caused almost half of the cells to die, it was used in the subsequent experiments.
Western blot analysis was used to investigate the effects of $\mathrm{H}_{2} \mathrm{O}_{2}$ insults on Sirt 3 expression, and the results revealed that incubation with $\mathrm{H}_{2} \mathrm{O}_{2}$ significantly increased the expression of Sirt3 in a dose-dependent manner ( $\mathrm{P}<0.05$; Fig. $1 \mathrm{C})$. As shown in Fig. 1D, a time-dependent increase in Sirt 3 expression was also observed following exposure to $500 \mu \mathrm{M} \mathrm{H}_{2} \mathrm{O}_{2}$.

$\mathrm{H}_{2} \mathrm{O}_{2}$-induced Sirt3 expression promotes HT22 cell survival. To investigate the biological functions of Sirt 3 in $\mathrm{H}_{2} \mathrm{O}_{2}$-induced neurotoxicity, the HT22 cells were transfected with Sirt3-specific siRNA (Si-Sirt3) or control siRNA (Si-Control). Western blot analysis indicated that Sirt3 expression was significantly reduced in the cells following transfection with $\mathrm{Si}-\mathrm{Sirt} 3$ ( $\mathrm{P}<0.05$; Fig. 2A). Following treatment with $500 \mu \mathrm{M} \mathrm{H}_{2} \mathrm{O}_{2}$ for $24 \mathrm{~h}$, the viability of the cells transfected with Si-Sirt3 was lower than that of the cells transfected with Si-Control (Fig. 2B). By contrast, the knockdown of Sirt3 further increased the release of LDH induced by $\mathrm{H}_{2} \mathrm{O}_{2}$ treatment in the HT22 cells (Fig. 2C). These data suggest that the knockdown of Sirt3 aggravates $\mathrm{H}_{2} \mathrm{O}_{2}$-induced neuronal injury and that $\mathrm{H}_{2} \mathrm{O}_{2}$-induced Sirt3 expression may be an endogenous protective mechanism.

Overexpression of Sirt3 reduces ROS generation and lipid peroxidation. To determine whether Sirt 3 affects the generation of intracellular ROS, the HT22 cells were transfected with lentivirus expressing Sirt3 (LV-Sirt3) or a control lentivirus (LV-Control). The results of western blot analysis indicated that the expression of Sirt3 was significantly increased by transfection with LV-Sirt3 as compared to transfection with the 

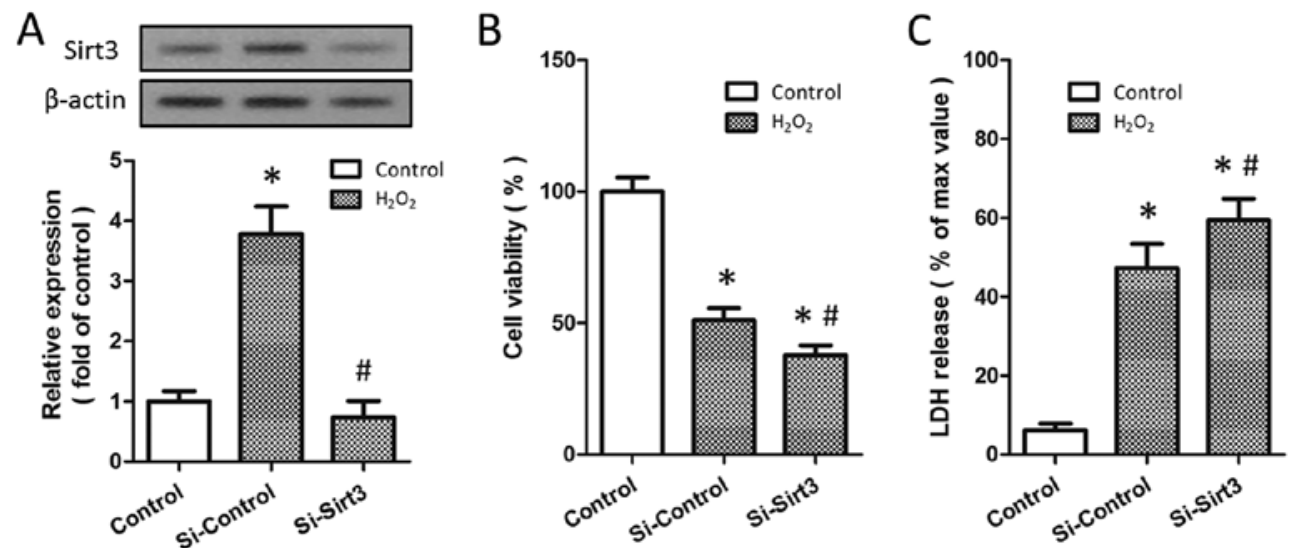

Figure 2. Downregulation of Sirt3 aggravates $\mathrm{H}_{2} \mathrm{O}_{2}$-induced cytotoxicity. HT22 cells were transfected with Sirt3-specific siRNA (Si-Sirt3) or control siRNA (Si-Control) for $72 \mathrm{~h}$, and then treated with or without $500 \mu \mathrm{M} \mathrm{H}_{2} \mathrm{O}_{2}$. (A) The expression of Sirt3 was measured by western blot analysis. Cell viability was measured by (B) WST-1 assay, and (C) cytotoxicity was measured by lactate dehydrogenase (LDH) assay. Data are shown as the means \pm SD of 5 experiments. ${ }^{*} \mathrm{P}<0.05$ vs. control. ${ }^{*} \mathrm{P}<0.05$ vs. Si-Control.
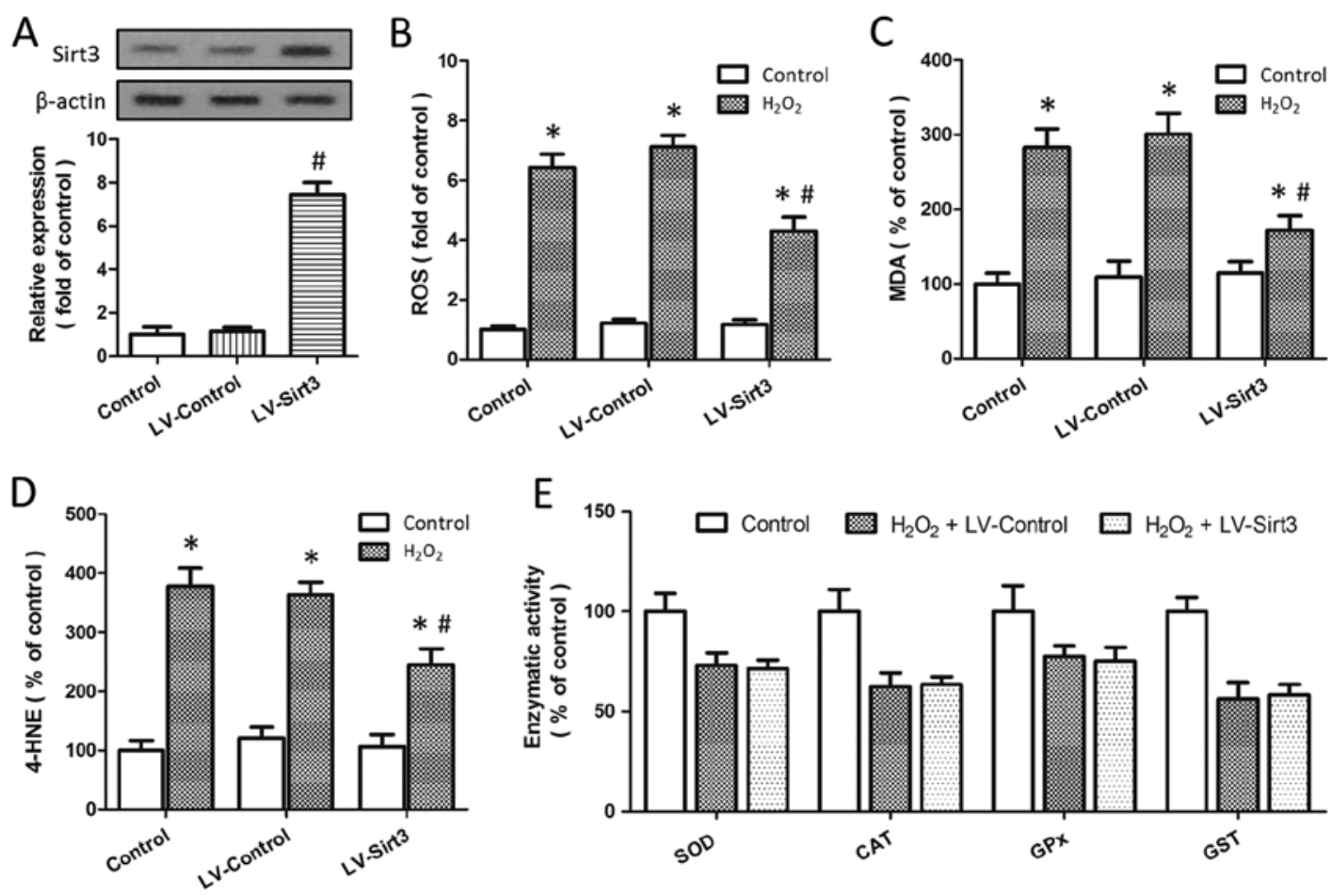

Figure 3. Overexpression of Sirt3 reduces reactive oxygen species (ROS) generation and lipid peroxidation. (A) HT22 cells were transfected with lentivirus expressing Sirt3 (LV-Sirt3) or control lentivirus (LV-Control) for $72 \mathrm{~h}$, and the expression of Sirt3 was measured by western blot analysis. (B) Following transfection, the HT22 cells were treated with or without $500 \mu \mathrm{M} \mathrm{H}_{2} \mathrm{O}_{2}$, and ROS production was measured by $\mathrm{H}_{2}$ DCFDA. The expression of (C) malonyldialdehyde (MDA) and (D) 4-hydroxynonenal (4-HNE), and (E) the enzymatic activity of superoxide dismutase (SOD), catalase (CAT), glutathione peroxidase (GPx) and glutathione S-transferase (GST) was assayed. Data are shown as the means $\pm \mathrm{SD}$ of 5 experiments. ${ }^{*} \mathrm{P}<0.05$ vs. control. ${ }^{*} \mathrm{P}<0.05$ vs. LV-Control.

LV-Control ( $\mathrm{P}<0.05$; Fig. 3A). ROS generation induced by $\mathrm{H}_{2} \mathrm{O}_{2}$ treatment was reduced by transfection with LV-Sirt3, but not by transfection with LV-Control (Fig. 3B). We also measured the expression levels of MDA and 4-HNE, 2 bioactive markers of lipid peroxidation, following $\mathrm{H}_{2} \mathrm{O}_{2}$-induced injury, and the results revealed that the knockdown of Sirt3 significantly decreased the levels of MDA (Fig. 3C) and 4-HNE (Fig. 3D) (both $\mathrm{P}<0.05$ ). As shown in Fig. 3E, treatment with $\mathrm{H}_{2} \mathrm{O}_{2}$ significantly inhibited the enzymatic activity of SOD, CAT, GPx and GST; however, neither LV-Sirt3 nor LV-Control had any effect on the enzymatic activity of these endogenous antioxidant enzymes, indicating the presence of an endogenous antioxidant system independent of the neuroprotective mechanisms.

To assess whether Sirt3 is enzymatically active under our experimental conditions, we detected the $\mathrm{NAD}^{+} / \mathrm{NADH}$ ratio following transfection and/or $\mathrm{H}_{2} \mathrm{O}_{2}$ treatment (Fig. 4). The results revealed that treatment with $\mathrm{H}_{2} \mathrm{O}_{2}$ significantly decreased the $\mathrm{NAD}^{+} / \mathrm{NADH}$ ratio compared with the control group, indicating that the enzymatic activity of Sirt3 was inhibited by oxidative stress in our in vitro model. The knock- 


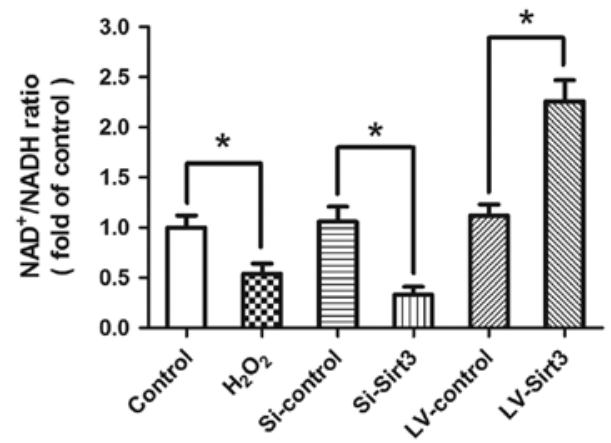

Figure 4. Effects of $\mathrm{H}_{2} \mathrm{O}_{2}$ treatment, Sirt 3 knockdown and Sirt 3 overexpression on the $\mathrm{NAD}^{+} / \mathrm{NADH}$ ratio. Following treatment with $\mathrm{H}_{2} \mathrm{O}_{2}$, and transfection with Sirt3-specific siRNA (Si-Sirt3), control siRNA (Si-Control), lentivirus expressing Sirt3 (LV-Sirt3) or control lentivirus (LV-Control) for $72 \mathrm{~h}$, the $\mathrm{NAD}^{+} / \mathrm{NADH}$ ratio was measured. Data are shown as the means $\pm \mathrm{SD}$ of 5 experiments. ${ }^{*} \mathrm{P}<0.05$

down of Sirt3 decreased the ratio of $\mathrm{NAD}^{+} / \mathrm{NADH}$, whereas the overexpression of Sirt3 by LV-Sirt3 transfection significantly increased the $\mathrm{NAD}^{+} / \mathrm{NADH}$ ratio.

Overexpression of Sirt3 preserves mitochondrial respiration and ATP production. The activity assays of electron transfer complexes I-IV in the cell homogenates were performed to investigate the effects of Sirt3 overexpression on mitochondrial respiration. The results revealed that the activity of complexes I-IV was markedly inhibited by $\mathrm{H}_{2} \mathrm{O}_{2}$ treatment (Fig. 5A). The overexpression of Sirt3 by LV-Sirt3 transfection significantly increased the activity of complexes I, III and IV following $\mathrm{H}_{2} \mathrm{O}_{2}$ insult, whereas the activity of complex II was not affected by Si-Sirt3 as compared to Si-Control $(\mathrm{P}>0.05)$. A dominant role for the mitochondria is the production of ATP through the electron transport chain. Thus, we measured ATP synthesis with a luciferase/luciferin-based system following mitochondrial isolation and purification. As shown in Fig. 5B, compared to the LV-Control-transfected cells, the overexpression of Sirt3 in the HT22 cells reversed the decrease in mitochondrial ATP production which was observed following treatment with $\mathrm{H}_{2} \mathrm{O}_{2}$.

Overexpression of Sirt3 blocks $\mathrm{H}_{2} \mathrm{O}_{2}$-induced mitochondrial dysfunction. To characterize the effects of Sirt3 on mitochondrial calcium homeostasis, we examined the calcium buffering capacity in isolated mitochondria following transfection and treatment with $\mathrm{H}_{2} \mathrm{O}_{2}$. As shown in Fig. 6A, the peaks corresponded to sequential bolus additions of $30 \mathrm{nM}$ of $\mathrm{Ca}^{2+}$, and the downward deflections reflected mitochondrial $\mathrm{Ca}^{2+}$ uptake. Treatment with $\mathrm{H}_{2} \mathrm{O}_{2}$ resulted in a $\sim 50 \%$ reduction in $\mathrm{Ca}^{2+}$ buffering capacity in the isolated mitochondria, whereas the overexpression of Sirt3 significantly preserved the $\mathrm{Ca}^{2+}$ buffering capacity compared to that in the LV-Control-transfected cells (Fig. 6B). Mitochondrial swelling under oxidative stress resulted in damage to the organelle, and is a signature of mitochondrial dysfunction. Thus, we also examined the effects of Sirt3 on mitochondrial swelling, which was induced by the addition of $200 \mu \mathrm{M} \mathrm{Ca}^{2+}$ into isolated mitochondria (Fig. 6C). The results revealed that the decreased absorbance at $540 \mathrm{~nm}$ induced by $\mathrm{H}_{2} \mathrm{O}_{2}$ treatment was partly prevented by LV-Sirt 3 transfection in
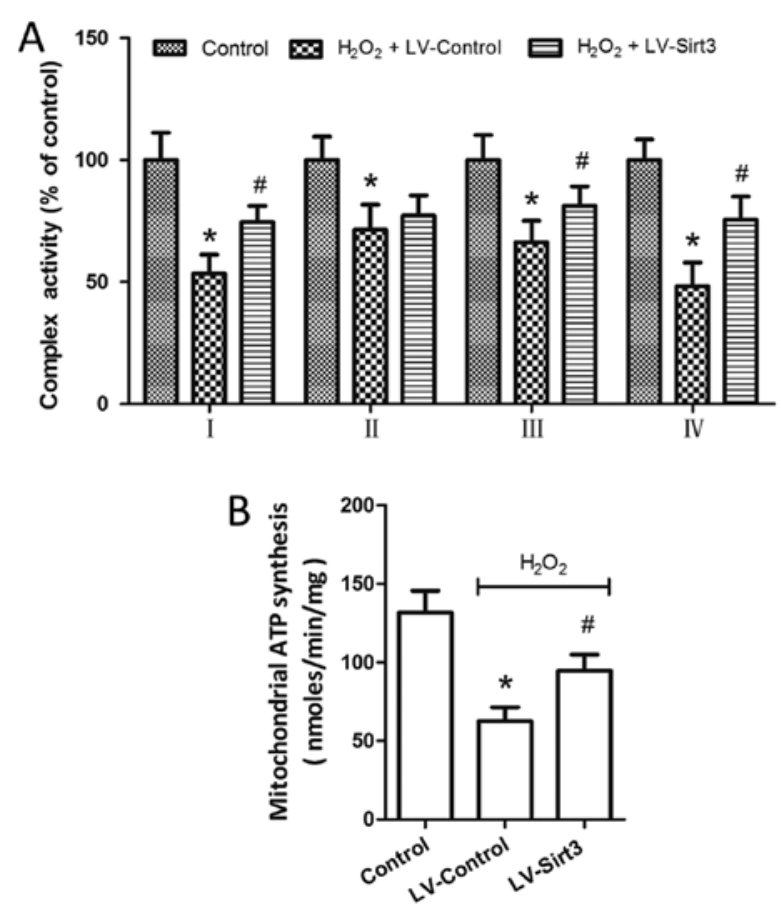

Figure 5. Overexpression of Sirt3 preserves mitochondrial respiration and adenosine triphosphate (ATP) synthesis. Following transfection with lentivirus expressing Sirt3 (LV-Sirt3) or control lentivirus (LV-Control) for $72 \mathrm{~h}$, the HT22 cells were treated with or without $500 \mu \mathrm{M} \mathrm{H}_{2} \mathrm{O}_{2}$, and the activity of mitochondrial respiratory chain complex I, complex II, complex III and complex IV was detected (A). (B) The levels of ATP synthesis in the mitochondria isolated from each group were measured. Data are shown as the means $\pm \mathrm{SD}$ of 5 experiments. ${ }^{*} \mathrm{P}<0.05$ vs. control. ${ }^{\#} \mathrm{P}<0.05$ vs. $\mathrm{LV}$-Control.

the HT22 cells, indicating that Sirt3 overexpression attenuated mitochondrial swelling following neuronal oxidative damage.

Overexpression of Sirt3 inhibits mitochondrial-associated apoptosis. To determine the protective effects of Sirt3 against apoptotic neuronal death induced by oxidative stress, flow cytometric analysis was performed at $24 \mathrm{~h}$ following treatment with $\mathrm{H}_{2} \mathrm{O}_{2}$. As shown in Fig. 7A, treatment with $\mathrm{H}_{2} \mathrm{O}_{2}$ resulted in apparent apoptotic cell death (evidenced by $\mathrm{AV}^{+} / \mathrm{PI}^{+}$and $\mathrm{AV}^{+} / \mathrm{PI}^{-}$cells) in the HT22 cells, and SIRT3 overexpression markedly decreased the number of early apoptotic cells and late apoptotic cells. We also measured the release of cytochrome $c$ into the cytoplasm by an immunoassay kit following subcellular fraction preparation. The results revealed that treatment with $\mathrm{H}_{2} \mathrm{O}_{2}$ induced a significant decrease in mitochondrial cytochrome $c$ and a marked increase in cytosolic cytochrome $c$; these effects were partly reversed by transfection with LV-Sirt3 (Fig. 7B and C). To further confirm the anti-apoptotic activity of Sirt3, we examined the expression of Bax, Bcl-2 and caspase-9 by western blot analysis (Fig. 7D). The Bax/Bcl-2 ratio and cleaved-caspase-9/caspase-9 ratio significantly increased following treatment with $\mathrm{H}_{2} \mathrm{O}_{2}$ (Fig. 7E and $\mathrm{F}$ ), whereas Sirt3 overexpression exerted a significant inhibitory effect on the $\mathrm{H}_{2} \mathrm{O}_{2}$-induced increase in the $\mathrm{Bax} / \mathrm{Bcl}-2$ ratio and cleaved-caspase- $9 /$ caspase- 9 ratio. The results of caspase- 3 activity assay indicated that Sirt3 overexpression also attenuated the activation of caspase- 3 induced by treatment with $\mathrm{H}_{2} \mathrm{O}_{2}$ (Fig. 7G). 

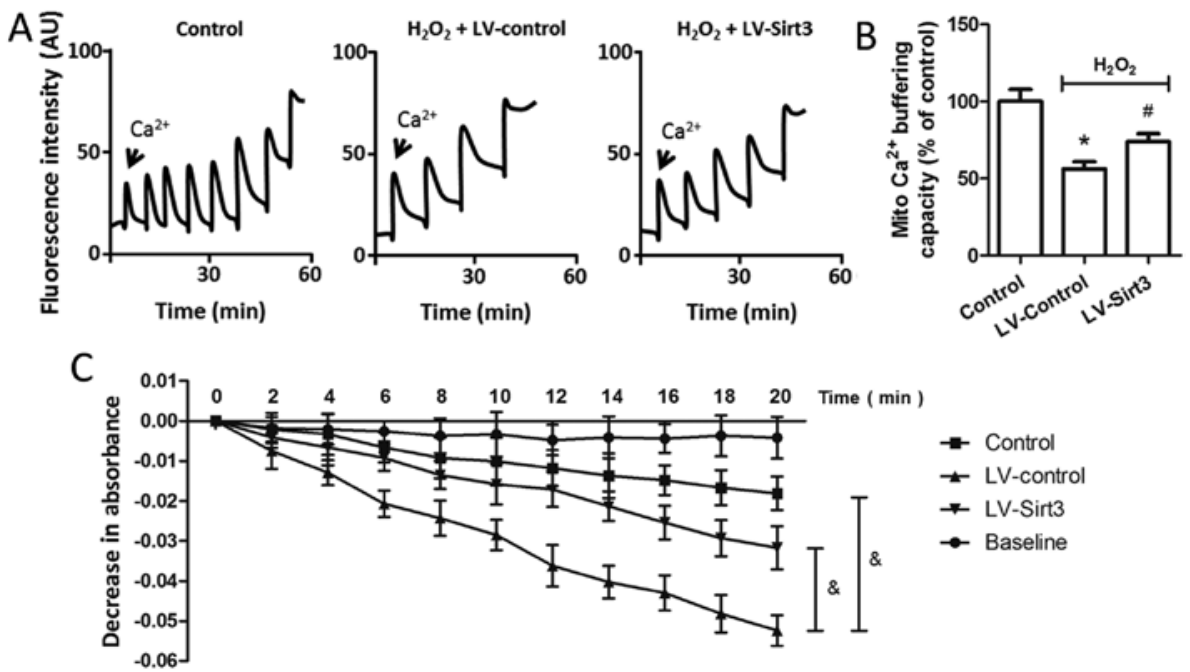

Figure 6. Overexpression of Sirt3 blocks $\mathrm{H}_{2} \mathrm{O}_{2}$-induced mitochondrial dysfunction. Following transfection with lentivirus expressing Sirt3 (LV-Sirt3) or control lentivirus (LV-Control) for $72 \mathrm{~h}$, the HT22 cells were treated with or without $500 \mu \mathrm{M} \mathrm{H}_{2} \mathrm{O}_{2}$, and the mitochondria in each group were isolated and purified Relative $\mathrm{Ca}^{2+}$ uptake capacity of isolated mitochondria was (A) determined and (B) calculated. Mitochondrial swelling was examined by monitoring the absorbance at $540 \mathrm{~nm}$ induced by $200 \mu \mathrm{M} \mathrm{Ca}^{2+}(\mathrm{C})$, and the baseline absorbance was measured without $\mathrm{Ca}^{2+}$. Data are shown as the means $\pm \mathrm{SD}$ of 5 experiments. ${ }^{*} \mathrm{P}<0.05$ vs. control. ${ }^{.} \mathrm{P}<0.05$ vs. LV-Control. ${ }^{\&} \mathrm{P}<0.05$. AU, arbitrary units.

A

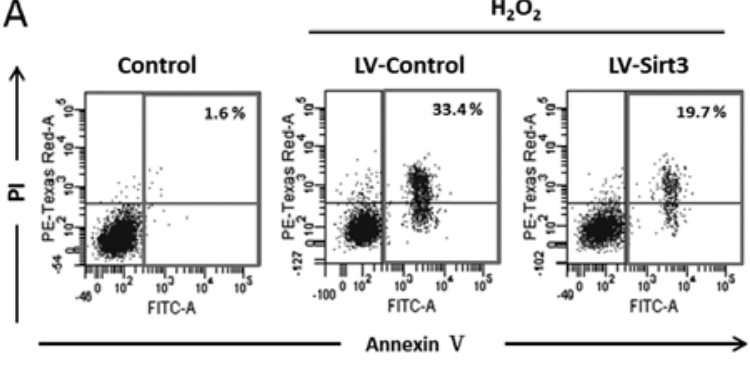

D

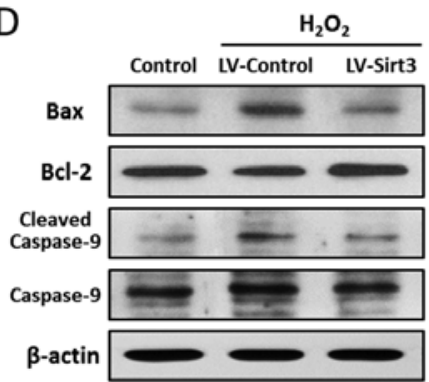

B
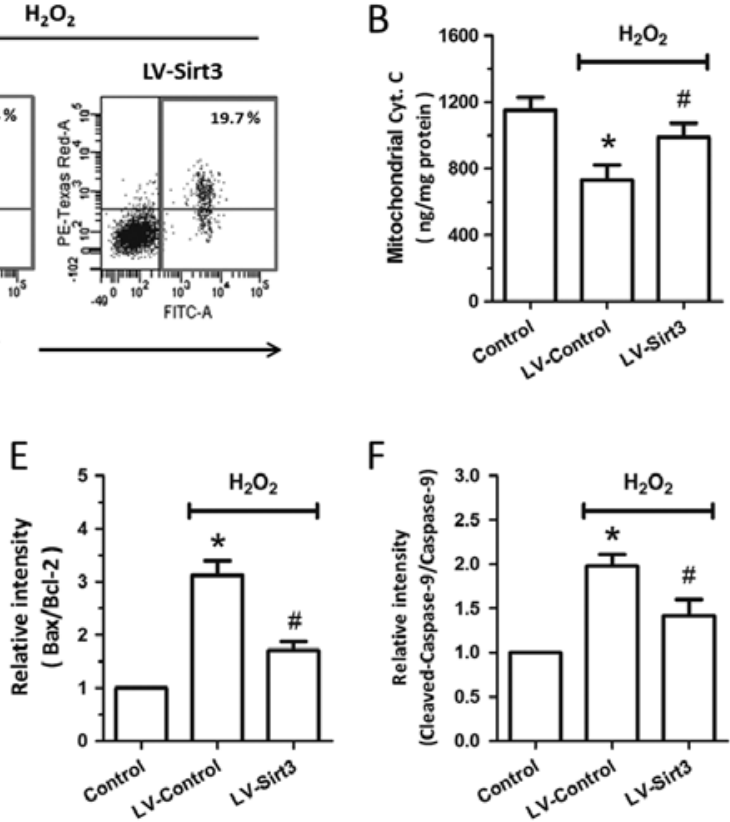

$F$

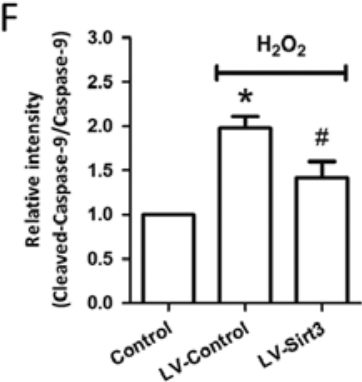

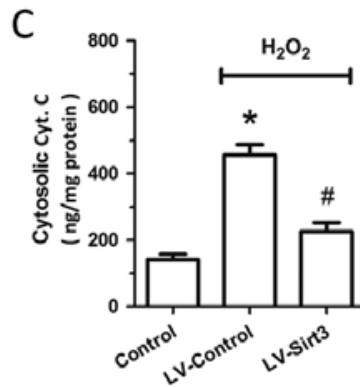

G

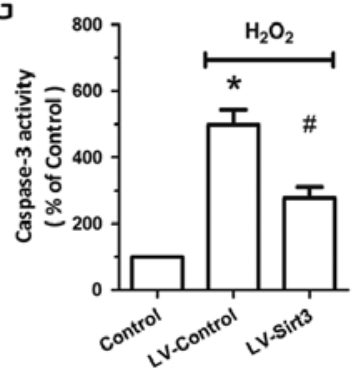

Figure 7. Overexpression of Sirt3 inhibits mitochondrial-associated apoptosis. Following transfection with lentivirus expressing Sirt3 (LV-Sirt3) or control lentivirus (LV-Control) for $72 \mathrm{~h}$, the HT22 cells were treated with or without $500 \mu \mathrm{M} \mathrm{H}_{2} \mathrm{O}_{2}$, and (A) apoptotic cell death was detected by flow cytometry. (B) Mitochondrial cytochrome $c$ and (C) cytosolic cytochrome $c$ were measured. (D) The expression levels of Bax, Bcl-2, cleaved caspase-9 and caspase-9 were determined by western blot analysis, and (E) the Bax/Bcl-2 ratio and (F) activity of caspase- 9 were calculated. (G) The activity of caspase- 3 was measured by an immunoassay kit. Data are shown as the means \pm SD of 5 experiments. ${ }^{*} \mathrm{P}<0.05$ vs. control. ${ }^{\#} \mathrm{P}<0.05$ vs. LV-Control.

\section{Discussion}

Mitochondrial proteins are acetylated at a high frequency (approximately 20\%), and acetylation is an important mechanism for the regulation of mitochondrial function through the modulation of protein-protein interactions, altering complex stability or affecting enzyme activities (18). Among the 3 members of the sirtuin family localized in the mitochondria (Sirt3, Sirt4 and Sirt5), which are referred to as mitochon- drial stress sensors (19), only Sirt3 has been demonstrated to robustly deacetylate mitochondrial proteins (20). The increased expression of Sirt3 has been shown to be associated with the extended lifespan of humans, and the Sirt3-mediated reprogramming of cellular metabolism may be of particular importance under oxidative stress conditions $(21,22)$. As previously demonstrated, cells in organs with high ATP demands (such as the heart, liver and brain) present higher levels of Sirt3 expression (23), which was also found in our in vitro neuronal 
model. The increased expression of Sirt 3 has also been observed in the heart under stress conditions, whereas Sirt3 levels are reduced in hypertrophied or failing hearts $(24,25)$. In the present study, we found that the expression of Sirt3 was increased following treatment with $\mathrm{H}_{2} \mathrm{O}_{2}$ in a dose- and timedependent manner, and the knockdown of Sirt3 by transfection with specific siRNA aggravated the $\mathrm{H}_{2} \mathrm{O}_{2}$-induced neuronal injury. These data indicate that Sirt3 may be an endogenous protective mechanism under oxidative stress conditions, and that the overexpression of Sirt3 may provide an incremental protective effect against $\mathrm{H}_{2} \mathrm{O}_{2}$ injury.

$\mathrm{H}_{2} \mathrm{O}_{2}$ is often considered to be a toxic molecule since it was discovered by Thénard in 1818. It has been implicated in several neuropathological conditions, such as brain trauma, cerebral ischemia and neurodegenerative diseases $(3,4)$. In previous studies, a marked and rapid increase in $\mathrm{H}_{2} \mathrm{O}_{2}$ levels was recorded in the reperfusion phase following transient brain ischemia (26), and the concentrations of $\mathrm{H}_{2} \mathrm{O}_{2}$ in rat vascular smooth muscle cells following ischemia and reperfusion injury were higher than $1 \mathrm{mM}(27) . \mathrm{H}_{2} \mathrm{O}_{2}$-induced oxidative stress and ROS generation contributes to cell death by the oxidation of several important lipids, proteins and nucleic acids, which further damage mitochondrial membrane integrity and inhibit energy production. In the present study, we found that the overexpression of Sirt3 attenuated the $\mathrm{H}_{2} \mathrm{O}_{2}$-induced ROS generation and lipid peroxidation, suggesting that Sirt3 activates the endogenous antioxidant system through the recruitment of antioxidants, such as SOD, CAT, GPx and GST, thereby attenuating $\mathrm{H}_{2} \mathrm{O}_{2}$-induced neuronal injury. To confirm this assumption, we also measured the enzymatic activity of SOD, CAT, GPx and GST following $\mathrm{H}_{2} \mathrm{O}_{2}$-induced injury in cells with or without Sirt3 overexpression. SOD, in its 3 isoforms (cytosolic $\mathrm{Cu}, \mathrm{Zn}-\mathrm{SOD}$, extracellular $\mathrm{Cu}, \mathrm{Zn}-\mathrm{SOD}$ and mitochondrial Mg-SOD), is responsible for $\mathrm{H}_{2} \mathrm{O}_{2}$ production from $\mathrm{O}^{-}$(28), and $\mathrm{H}_{2} \mathrm{O}_{2}$ is subsequently converted to $\mathrm{H}_{2} \mathrm{O}$ by GPx or decomposed in peroxisomes to $\mathrm{H}_{2} \mathrm{O}$ and $\mathrm{O}_{2}$ by CAT $(29,30)$. Accumulating evidence has suggested that the elevation of these endogenous antioxidants plays a protective role against $\mathrm{H}_{2} \mathrm{O}_{2}$-induced oxidative stress. Intriguingly, our results demonstrated that the overexpression of Sirt3 had no effect on the decreased enzymatic activity of SOD, CAT, GPx and GST induced by $\mathrm{H}_{2} \mathrm{O}_{2}$ insults, indicating the presence of an endogenous antioxidant system which is independent of the protective mechanisms of Sirt3 overexpression; this requires further investigation.

The electron transport chain (ETC) plays important roles in oxidative stress, not only due to its function in creating a transmembrane proton gradient, which is required for the generation of ATP through protons, but also as the dysregulated ECT function results in electron leak and increased ROS production through a series of protein complexes (I-IV) (9). Sirt3 physically interacts with the $39-\mathrm{kDa}$ protein, NADH dehydrogenase (ubiquinone) 1 alpha subcomplex 9 (NDUFA9), one of the known subunits of complex I, and regulates the complex I acetylation level and activity (23). Both the increased expression of Sirt3 and complex II activity have been observed in K562 cell lines following treatment with kaempferol (31). Recently, a 56-kDa core I subunit of complex III was identified as a potential target of Sirt3 by immunoprecipitation with anti-acetyl-lysine antibody from mitochondrial lysates (32).
Our results revealed that the overexpression of Sirt3 preserved the decreased activity of mitochondrial complex I, II and IV, and increased mitochondrial ATP synthesis following $\mathrm{H}_{2} \mathrm{O}_{2}$ induced injury. It is conceivable that the upregulation of Sirt3 preserves ATP generation in injured mitochondria to meet the cellular energy requirements, and this action of Sirt3 on mitochondrial energy metabolism may contribute to its neuroprotective effects against $\mathrm{H}_{2} \mathrm{O}_{2}$-induced oxidative injury.

Even though $\mathrm{Ca}^{2+}$ is well known as a crucial second messenger regulating cellular physiological functions, there are two opposite sides to the effects of $\mathrm{Ca}^{2+}$ on mitochondrial functions: it may either be beneficial for mitochondrial function in the processes of oxidative phosphorylation and ATP synthesis or it may be detrimental in instigating subsequent pathological cascades (33). Although the endoplasmic reticulum (ER) is considered to be the main site of intracellular $\mathrm{Ca}^{2+}$ storage, the mitochondria also serve as an important intracellular calcium buffer shaping $\mathrm{Ca}^{2+}$ signaling (34). Recent evidence has validated that mitochondrial $\mathrm{Ca}^{2+}$ loading plays crucial roles in apoptotic cell death under oxidative stress, possibly through nitric oxide production, cytochrome $c$ dissociation, mitochondrial permeability transition pore (mPTP) opening with the release of cytochrome $c$ and $\mathrm{Ca}^{2+}$ calmodulin dependent protein kinase activation (35). A previous study demonstrated that when exposed to $\mathrm{Ca}^{2+}$ under normoxic conditions, mitochondria isolated from rat cerebral cortex generate reactive hydroxyl $(\cdot \mathrm{OH})$, even in the absence of respiratory chain inhibitors (36). In the present study, we found that treatment with $\mathrm{H}_{2} \mathrm{O}_{2}$ resulted in a $\sim 50 \%$ reduction in $\mathrm{Ca}^{2+}$ buffering capacity in the isolated mitochondria, whereas the overexpression of Sirt3 significantly preserved the $\mathrm{Ca}^{2+}$ buffering capacity compared to that in the LV-Control-transfected cells. Considering the present data that the $\mathrm{Ca}^{2+}$ buffering capacity in the mitochondria decreases with the process of mitochondrial $\mathrm{Ca}^{2+}$ loading and the subcellular localization of Sirt3 in the mitochondria $(37,38)$, a hypothetical molecular mechanism explaining the relation between Sirt3 and the mitochondrial $\mathrm{Ca}^{2+}$ flux is that Sirt3 is involved in the $\mathrm{Ca}^{2+}$ transfer from the cytoplasm to the mitochondria through the regulation of mitochondrial calcium uniporters (mCU), such as uncoupling proteins (UCPs) and voltage-dependent anion channels (VDAC) (39). These data suggest that Sirt3 acts as a mitochondrial $\mathrm{Ca}^{2+}$ regulator through its interactions with other mitochondrial proteins; this requires confirmation in in vitro neuronal models.

The mitochondrion plays a prominent role in the induction of apoptotic cell death following oxidative stress. The mitochondria-associated intrinsic apoptotic pathway is mediated by the interplay between anti-apoptotic and pro-apoptotic Bcl-2 family proteins, which is initiated by the translocation of the pro-apoptotic protein, Bax, from the cytoplasm to the mitochondria (40). The disruption of mitochondrial membrane integrity and the opening of $\mathrm{mPTP}$ result in the release of cytochrome $c$, which further activates caspase- 9 and in turn causes the cleavage of caspase-3 $(40,41)$. Previous studies have indicated that under caloric restriction $(\mathrm{CR})$ conditions, the upregulated expression of Sirt3 directly deacetylates cyclophilin D (CypD), preventing its association with the adenine nucleotide translocator (ANT) and therefore blocking mPTP formation $(42,43)$. SIRT3 is required for the regulation of 
cytochrome $c$ superoxide-scavenging capacity through deacetylation and the activation of complex IV (44). However, the exact role of Sirt3 in apoptosis is contradictory, largely depending upon cell types. Previous studies have demonstrated the proapoptotic effects of Sirt3 in leucocythemia and colorectal cancer cells $(45,46)$, whereas the anti-apoptotic activity of Sirt3 and the Sirt3-mediated anti-apoptotic mechanisms have been reported by several other studies $(10,47,48)$. Recent observations also hint at additional neuroprotective effects of SIRT3, involving the regulation of mitochondrial dynamics $(9,49,50)$. In the present study, we found that the overexpression of Sirt3 significantly inhibited cytochrome $c$ release, the increase in the Bax/Bcl-2 ratio, as well as caspase-3 and caspase- 9 activation, and attenuated neuronal apoptosis following treatment with $\mathrm{H}_{2} \mathrm{O}_{2}$. These data indicate that the protective effects of Sirt3 in oxidative stress may partly be mediated by mitochondrialassociated apoptosis, and the anti-apoptotic activity of Sirt3 following treatment with $\mathrm{H}_{2} \mathrm{O}_{2}$ was confirmed in our in vitro neuronal injury model.

In conclusion, our results demonstrate that Sirt3 not only reduces $\mathrm{H}_{2} \mathrm{O}_{2}$-induced ROS overgeneration and lipid peroxidation, but also attenuates the mitochondrial dysfunction and subsequent activation of apoptosis. The increased expression of Sirt 3 induced by oxidative stress may be an endogenous protective mechanism, which is partly dependent on the preservation of mitochondrial calcium homeostasis. Thus, metabolic rescue observed upon the overexpression of Sirt3 may represent an appropriate strategy to avoid neuronal death in a broad range of neuronal disorders, where $\mathrm{H}_{2} \mathrm{O}_{2}$-related oxidative stress may play a major role, such as in cerebral ischemia-reperfusion injury and neurodegenerative diseases.

\section{Acknowledgements}

The present study was supported by grants from the National Natural Science Foundation of China (nos. 81071034, 81371447, 81301037,81200949 and 30930093), research funds from the government (nos. AWS11J008 and 2012BAI11B02) and the Program for Changjiang Scholars and Innovative Research Team in University (no. IRT1053).

\section{References}

1. Gough DR and Cotter TG: Hydrogen peroxide: a Jekyll and Hyde signalling molecule. Cell Death Dis 2: e213, 2011.

2. Plaine HL: The effect of oxygen and of hydrogen peroxide on the action of a specific gene and on tumor induction in drosophila melanogaster. Genetics 40: 268-280, 1955.

3. Halliwell B, Clement MV and Long LH: Hydrogen peroxide in the human body. FEBS Lett 486: 10-13, 2000.

4. Armogida M, Nistico R and Mercuri NB: Therapeutic potential of targeting hydrogen peroxide metabolism in the treatment of brain ischaemia. Br J Pharmacol 166: 1211-1224, 2012.

5. McBride HM, Neuspiel M and Wasiak S: Mitochondria: more than just a powerhouse. Curr Biol 16: R551-R560, 2006.

6. Chan PH: Mitochondria and neuronal death/survival signaling pathways in cerebral ischemia. Neurochem Res 29: 1943-1949, 2004.

7. Ye R, Yang Q, Kong X, et al: Ginsenoside Rd attenuates early oxidative damage and sequential inflammatory response after transient focal ischemia in rats. Neurochem Int 58: 391-398, 2011.

8. Michan S and Sinclair D: Sirtuins in mammals: insights into their biological function. Biochem J 404: 1-13, 2007.

9. Bause AS and Haigis MC: SIRT3 regulation of mitochondrial oxidative stress. Exp Gerontol 48: 634-639, 2013.
10. Sundaresan NR, Samant SA, Pillai VB, Rajamohan SB and Gupta MP: SIRT3 is a stress-responsive deacetylase in cardiomyocytes that protects cells from stress-mediated cell death by deacetylation of Ku70. Mol Cell Biol 28: 6384-6401, 2008.

11. Tseng AH, Shieh SS and Wang DL: SIRT3 deacetylates FOXO3 to protect mitochondria against oxidative damage. Free Radic Biol Med 63: 222-234, 2013.

12. D'Aquila P, Rose G, Panno ML, Passarino G and Bellizzi D SIRT3 gene expression: a link between inherited mitochondrial DNA variants and oxidative stress. Gene 497: 323-329, 2012.

13. Estornell E, Fato R, Pallotti F and Lenaz G: Assay conditions for the mitochondrial NADH:coenzyme Q oxidoreductase. FEBS Lett 332: 127-131, 1993.

14. Dave KR, DeFazio RA, Raval AP, et al: Ischemic preconditioning targets the respiration of synaptic mitochondria via protein kinase C epsilon. J Neurosci 28: 4172-4182, 2008.

15. Krahenbuhl S, Chang M,BrassEPand HoppelCL:Decreased activities of ubiquinol:ferricytochrome c oxidoreductase (complex III) and ferrocytochrome c:oxygen oxidoreductase (complex IV) in liver mitochondria from rats with hydroxycobalamin[c-lactam]induced methylmalonic aciduria. J Biol Chem 266: 20998-21003, 1991.

16. Parone PA, Da Cruz S, Han JS, et al: Enhancing mitochondrial calcium buffering capacity reduces aggregation of misfolded SOD1 and motor neuron cell death without extending survival in mouse models of inherited amyotrophic lateral sclerosis. J Neurosci 33: 4657-4671, 2013.

17. Yu Z, Liu N, Li Y, Xu J and Wang X: Neuroglobin overexpression inhibits oxygen-glucose deprivation-induced mitochondrial permeability transition pore opening in primary cultured mouse cortical neurons. Neurobiol Dis 56: 95-103, 2013.

18. Kim SC, Sprung R, Chen Y, et al: Substrate and functional diversity of lysine acetylation revealed by a proteomics survey. Mol Cell 23: 607-618, 2006.

19. Huang JY, Hirschey MD, Shimazu T, Ho L and Verdin E: Mitochondrial sirtuins. Biochim Biophys Acta 1804: 1645-1651, 2010.

20. Verdin E, Hirschey MD, Finley LW and Haigis MC: Sirtuin regulation of mitochondria: energy production, apoptosis, and signaling. Trends Biochem Sci 35: 669-675, 2010.

21. Bellizzi D, Rose G, Cavalcante P, et al: A novel VNTR enhancer within the SIRT3 gene, a human homologue of SIR2, is associated with survival at oldest ages. Genomics 85: 258-263, 2005.

22. Rose G, Dato S, Altomare K, et al: Variability of the SIRT3 gene, human silent information regulator Sir2 homologue, and survivorship in the elderly. Exp Gerontol 38: 1065-1070, 2003.

23. Ahn BH, Kim HS, Song S, et al: A role for the mitochondrial deacetylase Sirt3 in regulating energy homeostasis. Proc Natl Acad Sci USA 105: 14447-14452, 2008.

24. Pillai VB, Sundaresan NR, Kim G, et al: Exogenous NAD blocks cardiac hypertrophic response via activation of the SIRT3-LKB1AMP-activated kinase pathway. J Biol Chem 285: 3133-3144, 2010.

25. Sundaresan NR, Gupta M, Kim G, Rajamohan SB, Isbatan A and Gupta MP: Sirt3 blocks the cardiac hypertrophic response by augmenting Foxo3a-dependent antioxidant defense mechanisms in mice. J Clin Invest 119: 2758-2771, 2009.

26. Lei $\mathrm{B}$, Adachi $\mathrm{N}$ and Arai T: Measurement of the extracellular $\mathrm{H}_{2} \mathrm{O}_{2}$ in the brain by microdialysis. Brain Res Brain Res Protoc 3: 33-36, 1998.

27. Sundaresan M, Yu ZX, Ferrans VJ, Irani K and Finkel T: Requirement for generation of $\mathrm{H}_{2} \mathrm{O}_{2}$ for platelet-derived growth factor signal transduction. Science 270: 296-299, 1995.

28. Fridovich I: Superoxide radical and superoxide dismutases. Annu Rev Biochem 64: 97-112, 1995.

29. Dringen R: Oxidative and antioxidative potential of brain microglial cells. Antioxid Redox Signal 7: 1223-1233, 2005.

30. Dringen R, Pawlowski PG and Hirrlinger J: Peroxide detoxification by brain cells. J Neurosci Res 79: 157-165, 2005.

31. Cimen H, Han MJ, Yang Y, Tong Q, Koc H and Koc EC: Regulation of succinate dehydrogenase activity by SIRT3 in mammalian mitochondria. Biochemistry 49: 304-311, 2010.

32. Jing E, Emanuelli B, Hirschey MD, et al: Sirtuin-3 (Sirt3) regulates skeletal muscle metabolism and insulin signaling via altered mitochondrial oxidation and reactive oxygen species production. Proc Natl Acad Sci USA 108: 14608-14613, 2011.

33. Brookes PS, Yoon Y, Robotham JL, Anders MW and Sheu SS: Calcium, ATP, and ROS: a mitochondrial love-hate triangle. Am J Physiol Cell Physiol 287: C817-C833, 2004. 
34. Rizzuto R, De Stefani D, Raffaello A and Mammucari C: Mitochondria as sensors and regulators of calcium signalling. Nat Rev Mol Cell Biol 13: 566-578, 2012.

35. Peng TI and Jou MJ: Oxidative stress caused by mitochondrial calcium overload. Ann NY Acad Sci 1201: 183-188, 2010.

36. Dykens JA: Isolated cerebral and cerebellar mitochondria produce free radicals when exposed to elevated $\mathrm{CA}^{2+}$ and $\mathrm{Na}^{+}$ implications for neurodegeneration. J Neurochem 63: 584-591, 1994.

37. Contreras L, Drago I, Zampese E and Pozzan T: Mitochondria: the calcium connection. Biochim Biophys Acta 1797: 607-618, 2010.

38. Giralt A and Villarroya F: SIRT3, a pivotal actor in mitochondrial functions: metabolism, cell death and aging. Biochem J 444: 1-10, 2012.

39. Shi T, Wang F, Stieren E and Tong Q: SIRT3, a mitochondrial sirtuin deacetylase, regulates mitochondrial function and thermogenesis in brown adipocytes. J Biol Chem 280: 13560-13567, 2005.

40. Del Gaizo Moore V and Letai A: BH3 profiling - measuring integrated function of the mitochondrial apoptotic pathway to predict cell fate decisions. Cancer Lett 332: 202-205, 2013.

41. Hacker G and Paschen SA: Therapeutic targets in the mitochondrial apoptotic pathway. Expert Opin Ther Targets 11: 515-526, 2007.

42. Hafner AV, Dai J, Gomes AP, et al: Regulation of the mPTP by SIRT3-mediated deacetylation of CypD at lysine 166 suppresses age-related cardiac hypertrophy. Aging 2: 914-923, 2010.
43. Shulga N, Wilson-Smith R and Pastorino JG: Sirtuin-3 deacetylation of cyclophilin D induces dissociation of hexokinase II from the mitochondria. J Cell Sci 123: 894-902, 2010.

44. Kong X, Wang R, Xue Y, et al: Sirtuin 3, a new target of PGC-1alpha, plays an important role in the suppression of ROS and mitochondrial biogenesis. PloS One 5: e11707, 2010.

45. Marfe G, Tafani M, Indelicato M, et al: Kaempferol induces apoptosis in two different cell lines via Akt inactivation, Bax and SIRT3 activation, and mitochondrial dysfunction. J Cell Biochem 106: 643-650, 2009.

46. Allison SJ and Milner J: SIRT3 is pro-apoptotic and participates in distinct basal apoptotic pathways. Cell Cycle 6: 2669-2677, 2007.

47. Yang H, Yang T, Baur JA, et al: Nutrient-sensitive mitochondrial $\mathrm{NAD}^{+}$levels dictate cell survival. Cell 130: 1095-1107, 2007.

48. Kim SH, Lu HF and Alano CC: Neuronal Sirt3 protects against excitotoxic injury in mouse cortical neuron culture. PloS One 6: e14731, 2011.

49. Kincaid B and Bossy-Wetzel E: Forever young: SIRT3 a shield against mitochondrial meltdown, aging, and neurodegeneration. Front Aging Neurosci 5: 48, 2013.

50. Rato L, Duarte AI, Tomas GD, et al: Pre-diabetes alters testicular PGC1-alpha/SIRT3 axis modulating mitochondrial bioenergetics and oxidative stress. Biochim Biophys Acta 1837: 335-344, 2014. 